\title{
Biochemical Markers and Cardiovascular Outcome in Maintenance Hemodialysis Patients
}

\author{
Nadia Y. S. Morcos ${ }^{1 *}$, Emam A. Waked ${ }^{2}$, Eman M. Saleh ${ }^{1}$ and Marwa A. Mohamed ${ }^{2}$ \\ ${ }^{I}$ Department of Biochemistry, Faculty of Science, Ain Shams University, 11566, Cairo, Egypt, \\ ${ }^{2}$ Nephrology Department Theodor Bilharz Research Institute, Cairo, Egypt.
}

\section{A R T ICLE INFO}

Article history:

Received 12 July 2015

Accepted 22 September 2015

Keywords:

Mortality rate;

Hemodialysis;

Gender/age factor;

Electrocardiographic

examination.

\begin{abstract}
A B S T R A C T
Worldwide the number of patients requiring chronic hemodialysis (HD) is rapidly growing. Hemodialysis greatly reduces quality of life and it is associated with extremely high mortality rates. The present study was planned to study the impact of age and gender on cardiovascular death markers in a sample of Egyptian patients, maintained on hemodialysis. In an observational cohort study we investigated 70 non-diabetic patients on maintenance hemodialysis (MHD). All

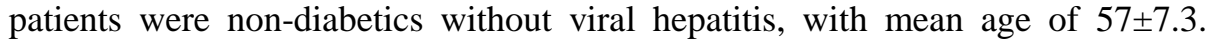
Patients were divided into subgroups according to gender, age (age was dichotomized as $<$ or $\geq 60$ years), and survival. Fifteen matching controls were included for reference values. All subjects underwent blood analysis before the commencement of hemodialysis, and echocardiography during follow-up. Patients were followed for 4 years, and cardiovascular mortality rate was recorded. A total of 45 patients died (64.3\%), all of them suffered from cardiovascular complications. The first echocardiographic examination and rate of mortality did not differ among the subgroups. Although the overall relative risk of cardiovascular mortality was equivalent between men and women, age had a significant interaction with gender on the overall biochemical markers. Compared with patients who survived, women who died and were younger than 60 years old had lower albumin and higher globulin serum levels. However, deceased women older than 60 years, had lower urea and high-sensitive C-reactive protein (Hs CRP), together with higher LDL, LDL/HDL ratio, and bone-specific alkaline phosphatase (B-ALP) activity. These differences were not recorded in male patients. In patients maintained on hemodialysis, both sexes face increased risk of cardiovascular complications. However, gender and age together play significant role in determining biochemical predictors for cardiovascular mortality.
\end{abstract}

\section{Introduction}

The prevalence of chronic kidney disease (CKD), is still growing worldwide, conferring a higher risk of coronary artery disease, chronic heart failure and/or death ${ }^{[1]}$.The elevated risk of cardiovascular morbidity and mortality in this population is well established and often precedes progression to end-stage renal disease (ESRD) and dialysis. Historically, the cardiovascular death associated with CKD had been attributed to the complications of atherosclerotic disease. A substantial proportion of cardiac deaths, however, is not directly linked to myocardial infarction, stroke, or heart failure suggesting the presence of other processes contributing to cardiovascular $(\mathrm{CV})$ mortality ${ }^{[2]}$.

\footnotetext{
* Corresponding author.

E-mail address: nadiamrcs@googlemail.com
}

The high incidence of cardiovascular morbidity and mortality in ESRD warrants an accurate evaluation of risk aimed at reducing the burden of disease and its consequences. In ESRD patients, numerous markers similar to those used in the general population and others more specific to the uremic population have emerged (anemia, oxidative stress, inflammation, and bone mineral disorders) ${ }^{[2]}$. However, recent studies revealed that traditional risk factors for atherosclerosis do not account for the majority of risk of CV events associated with ESRD ${ }^{[3]}$. Moreover, revascularization or aggressive treatment of CV risk factors have had little, or at best modest, success in preventing adverse cardiac events particularly among dialysis patients, suggesting that pathogenic mechanisms other than obstructive coronary artery disease may contribute to excess $\mathrm{CV}$ 
complications in those with $\mathrm{CKD}^{[3]}$.

End-stage renal disease occurs when chronic renal failure progresses to the point that the kidneys are permanently functioning at less than $10 \%$ of their capacity, i.e., the glomerular filtration rate (GFR) is permanently lower than $15 \mathrm{ml} / \mathrm{min} / 1.73 \mathrm{~m}^{2}$. Electrolyte alterations and extra-renal disorders are quite frequent in patients subjected to hemodialysis (HD) ${ }^{[4]}$. The clinical constellation of signs and symptoms of ESRD is known as uremic syndrome. Patients with ESRD are susceptible to all complications of any underlying condition such as diabetes and hypertension as well as other metabolic and physiologic derangements ${ }^{[5]}$.

Given the potential interplay between kidney function, biochemical disturbances and cardiovascular morbidity and mortality, this investigation examined whether predialysis measures of some simple biochemical markers were predictive for development of cardiovascular mortality in non-diabetic Egyptians patients.

\section{Subjects and methods}

A total of 70 non-diabetic patients; of both sexes, subjected to maintenance hemodialysis (MHD) (age = $58 \pm 7$ years) were chosen for this study. They were chosen from Theodor Bilharz Research Institute Hospital. Patients underwent hemodialysis sessions three times a week, with mean duration of $5.9 \pm 1.8$ years. Patients with diabetes and viral hepatitis were excluded. During dialysis all patients were treated according the protocol of the institute, and were observed for cardiovascular complications (CC) including mortality for $\mathbf{4}$ years. The control group consisted of 15 age matching healthy subjects, and their data were used for reference range only. Biochemical analyses were done once after 12 hours fasting before subjecting the patients to dialysis (baseline). Clinical examinations were carried out after the first session of dialysis and then periodically every 6 months throughout the follow-up period, complications were recorded after each examination.

All subjects enrolled in this study were informed about its purpose and methodology and signed a consent form. The study was approved by the Bioethics Committee of Theodor Bilharz Research Institute Hospital. Cardiac echocardiography was performed to all cases by Standard transthoracic M. mode, two dimensional, continuous and pulsed wave Doppler echocardiograms, using 2.5 $\mathrm{MHz}$ transducer. Carotid duplex was performed to assess heart condition and function, the presence of left ventricular hypertrophy, together with systolic and diastolic function disturbances. Both cardiac echocardiography and carotid duplex were carried out by Aloka prosound SSD-3500 SV: Hitachi Aloka medical (Japan). These data were further analyzed to study their connection with mortality during the followup period (4 years). The first cardiac indices measured are given in Table 1.

Biochemical analyses were carried out once on Clinilab 20 at the beginning before starting hemodialysis, using commercial kits purchased from Clinilab (U.S.A), unless otherwise mentioned. They included; renal function markers; creatinine (kinetic colorimetric method, according to Jaffe ${ }^{[6]}$ ), and urea (modified urease Berthlot colorimetric method) ${ }^{[7]}$, fasting glucose (enzymatic colorimetric method) ${ }^{[8]}$. Calcium and phosphorous were determined by colorimetric endpoint method ${ }^{[9]}$ and ${ }^{[10]}$, respectively. The liver function markers included; aspartate aminotransaminase (AST) and alanine aminotransaminase (ALT) (according to Reitman \& Frankel ${ }^{[11]}$ ), gamma glutamyl transferase (GGT) (quantitative kinetic method of Szasz ${ }^{[12]}$ ), total bilirubin ${ }^{[13]}$, total protein (by Biuret reaction) ${ }^{[14,15]}$, and albumin (by bromocresol green) ${ }^{[16,17]}$, while globulin was calculated (Globulin conc. $(\mathrm{g} / \mathrm{L})=$ Total Protein Albumin). The bone enzymes included total alkaline phosphatase (ALP) determined by (IFCC ${ }^{[18]}$ ), and serum bone-alkaline phosphatase (B-ALP) (using the Beckman coulter access 2: (Beckman Coulter, Inc. U.S.A) ${ }^{[19]}$. Intact parathyroid hormone (iPTH) was determined by solid-phase, two-side chemiluminescent enzyme-labeled immunometric assay ${ }^{[20,21]}$. The inflammation markers $\mathrm{C}$ - reactive protein (CRP) and high-sensitive CRP (Hs CRP) were determined by turbidometric immunoassay methods ${ }^{[22}$ and 23 , respectively] , using Siemens kits, and were carried out on Immulite 1000 Siemens (Germany). Enzymatic colorimetric methods were used for total cholesterol ${ }^{[24,25]}$, and triglycerides (TG) ${ }^{[26,27]}$. HDLcholesterol was determined as cholesterol after precipitation of LDL and VLDL [28,29] using Spectrometer 5010: Robert Riele $\mathrm{GmbH}$ \& Co KG (Germany). LDL-cholesterol was calculated (LDLcholesterol $=$ total cholesterol - HDL-cholesterol - TG/5). Detection of hepatitis viruses was done by enzyme immunoassay for the detection of antibodies against Human Hepatitis Virus Type $\mathrm{C}(\mathrm{HCV})^{[30]}$, and Hepatitis B surface antigen (HBs-Ag) ${ }^{[31]}$ carried out on Fully Automated Elisa TC 92 microplate: Teco diagnostics (U.S.A). Hemoglobin ${ }^{[32]}$, and hematocrit (HCT) ${ }^{[33]}$ were determined by kits from Bechman coulter Int., carried out on Bechman coulter AcT diff (U.S.A).

\section{Statistical analysis:}

All data were analyzed for normality of distribution and equality of standard deviations before analysis. Continuous data are presented as the mean \pm SE. Categorical data are presented as number and percentages. Statistical differences between continuous variables were determined using Mann-Whitney test; since the data were heterogeneously distributed, or Chisquared test for categorical variables. Descriptive analyses were also used to summarize baseline characteristics of the study participants according to their final event status (i.e., alive vs. dead), followed by correlation analysis. Receiver operating characteristic (ROC) curves were done to compare the diagnostic performance of two or more of the tests, and calculate their cutoff values. A $P$ value $<0.05$ was considered statistically significant. Analyses were carried out using the SPSS 21.0 statistical package (SPSS, Chicago, IL). 
Table 1: Demographic and Echocardiographic examinations of controls and patients; those who survived and those who died (Mann-Whitney Test).

\begin{tabular}{|c|c|c|c|c|c|c|}
\hline & \multicolumn{2}{|c|}{ Groups } & \multirow{3}{*}{$\mathbf{P}$} & \multicolumn{2}{|c|}{ Survival } & \multirow{3}{*}{$\mathbf{P}$} \\
\hline & Control & Patients & & Alive & Dead & \\
\hline & Mean \pm SE & Mean $\pm \mathrm{SE}$ & & Mean \pm SE & Mean \pm SE & \\
\hline Number & 15 & 70 & & 25 & 45 & \\
\hline Gender Males/Females & $11 / 4$ & $51 / 19$ & NS & 18/7 & $33 / 12$ & NS \\
\hline Age (y) & $51.7 \pm 2.6$ & $57 \pm 0.87$ & NS & $56.7 \pm 1.5$ & $57.2 \pm 1.1$ & NS \\
\hline Males $<60$ & $8(53.3 \%)$ & $29(41.4 \%)$ & NS & $11(44 \%)$ & $18(40 \%)$ & NS \\
\hline Males $\geq 60$ & $3(20 \%)$ & $22(31.4 \%)$ & NS & $7(28 \%)$ & $15(33 \%)$ & NS \\
\hline Females $<60$ & $4(26.7 \%)$ & $10(14.3 \%)$ & NS & $3(12 \%)$ & $7(15.6 \%)$ & NS \\
\hline Femaless $\geq 60$ & $\mathbf{0}(\mathbf{0 \%})$ & $9(12.9 \%)$ & NS & $4(16 \%)$ & $5(11 \%)$ & NS \\
\hline Duration of dialysis (years) & & $5.9 \pm 0.21$ & NS & $5.7 \pm 0.4$ & $5.9 \pm 2.4$ & NS \\
\hline Systolic BP. mmHg & $118 \pm 1.9$ & $129.1 \pm 2.3$ & 0.010 & $124.4 \pm 4.2$ & $131.7 \pm 2.7$ & NS \\
\hline Diastolic BP. mmHg & $79 \pm 1.2$ & $80.1 \pm 1.4$ & NS & $76.8 \pm 2.6$ & $82.0 \pm 1.6$ & NS \\
\hline Posterior wall dimension $\mathrm{Mm}$ & $8.9 \pm 0.3$ & $37.6 \pm 1.1$ & 0.001 & $1.11 \pm 0.04$ & $1.10 \pm 0.03$ & NS \\
\hline $\begin{array}{c}\text { Interventricular septal end } \\
\text { diastolic dimension } \mathrm{Mm}\end{array}$ & $9.0 \pm 0.3$ & $63.2 \pm 1.2$ & 0.001 & $36.7 \pm 1.5$ & $38.1 \pm 1.5$ & NS \\
\hline Ejection fraction \% & $70.6 \pm 1.7$ & $11.5 \pm 0.28$ & 0.001 & $63.4 \pm 2.2$ & $63.1 \pm 1.5$ & NS \\
\hline Fractional shortening \% & $40.6 \pm 1.4$ & $11.6 \pm 0.23$ & 0.001 & $11.0 \pm 0.4$ & $11.7 \pm 0.36$ & NS \\
\hline End-systolic dimension Mm & $30.4 \pm 1.4$ & $28.9 \pm 0.61$ & NS & $11.5 \pm 0.4$ & $11.6 \pm 0.28$ & NS \\
\hline End-diastolic dimension Mm & $51.1 \pm 2.1$ & $37.94 \pm 0.76$ & 0.001 & $29.4 \pm 1.1$ & $28.6 \pm 0.73$ & NS \\
\hline Left atrial dimension $\mathrm{Mm}$ & $35.1 \pm 0.74$ & $49.6 \pm 1.0$ & 0.001 & $37.6 \pm 1.2$ & $38.1 \pm 0.97$ & NS \\
\hline Aorta Mm & $28.9 \pm 0.74$ & $33.4 \pm-.64$ & 0.001 & $48.8 \pm 1.9$ & $50.0 \pm 1.2$ & NS \\
\hline Intima-media thickness Mm & $0.69 \pm 0.03$ & $1.1 \pm 0.2$ & 0.001 & $33.6 \pm 0.9$ & $33.4 \pm 0.9$ & NS \\
\hline
\end{tabular}

\section{Results:}

\section{Characteristics of studied groups}

The average age (mean \pm SE) of patients group was $57 \pm 0.87$ years and for controls $51.7 \pm 2.6$. The ratio of Men: Women (11:4 control; 51:19 patients) did not differ among both groups, where men represented nearly $73 \%$. Distribution of age among the subgroups showed no significant differences, also between patients who were alive and those who died within 4 years (Table 1).

Analysis of echocardiographic indices

Before the second session of dialysis echocardiographic examinations were carried out to all subjects. Results revealed that patients in comparison with the control group had significantly higher interventricular septal end diastolic dimension, and much smaller diastolic dimensions of the left ventricle. These patients also had a significantly greater left atrial dimension.

Chronic kidney disease patients were also more likely to have aortic valve calcification and their ejection fraction was significantly lower than in the control group. Although their systolic blood pressure was higher than controls, still it was within normal values. These observations confirm the adverse effect of renal disease on the cardiovascular system ${ }^{[34]}$. However, these abnormalities were not statistically different in patients who died within 4 years from those who remained alive (Table 1).

\section{Analysis of the biochemical parameters}

Control values were used for reference ranges only. The differences in the biochemical markers between patients and controls are given in Table 2. Statistically significant decrease in hemoglobin, hematocrit, total cholesterol, triglycerides, HDL, LDL, ALT, AST, GGT, and calcium were observed in patients compared to controls. On the other hand, patients had higher creatinine, urea, CRP, Hs CRP, ALP, B-ALP, phosphorous, and $\mathrm{Ca} \times \mathrm{P}$ levels. However, these abnormalities were not statistically different in patients who died within 4 years from those who remained alive (Table 2).

Cardiovascular complications and mortality rate

Mortality data are represented in Table 3. A total of 45 patients $(64.3 \%)$ died from cardiovascular complications during the 4 years of follow-up. This rate did not differ by age or gender. 
Table 2: Biochemical parameters in controls, patients, survived and died (mean \pm SE; Mann-Whitney Test).

\begin{tabular}{|c|c|c|c|c|c|c|}
\hline & Control & Patients & $\boldsymbol{P}$ & Survived & Died & $\boldsymbol{P}$ \\
\hline Hemoglobin g/dL & $12.8 \pm 0.26$ & $9.0 \pm 0.22$ & 0.001 & $9 \pm 0.39$ & $9 \pm 0.27$ & NS \\
\hline Hematocrit \% & $38.7 \pm 0.77$ & $27.1 \pm 0.67$ & 0.001 & $27.0 \pm 1.2$ & $27.1 \pm 0.81$ & NS \\
\hline Creatinine mg/dL & $1.19 \pm 0.04$ & $8.1 \pm 0.23$ & 0.001 & $8.6 \pm 0.42$ & $7.9 \pm 0.67$ & NS \\
\hline Urea mg/dL & $29.5 \pm 1.1$ & $131.5 \pm 3.7$ & 0.001 & $132 \pm 6.3$ & $131.2 \pm 4.7$ & NS \\
\hline Blood glucose mg/dL & $91.7 \pm 2.7$ & $97.1 \pm 2.5$ & NS & $96.0 \pm 2.2$ & $97.7 \pm 3.8$ & NS \\
\hline T. Cholesterol mg/dL & $188.8 \pm 3.0$ & $147.6 \pm 5.2$ & 0.001 & $151.7 \pm 8.5$ & $145.4 \pm 6.6$ & NS \\
\hline Triglycerides mg/dL & $151.2 \pm 3.1$ & $119.1 \pm 14.8$ & 0.002 & $143.8 \pm 34.7$ & $105.4 \pm 12.6$ & NS \\
\hline HDL-C mg/dL & $53.9 \pm 3.5$ & $37.6 \pm 0.52$ & 0.001 & $37.9 \pm 0.88$ & $37.4 \pm 0.66$ & NS \\
\hline LDL-C mg/dL & $104.6 \pm 5.9$ & $87 \pm 4.6$ & 0.05 & $84.9 \pm 7.8$ & $82.2 \pm 5.7$ & NS \\
\hline Cholesterol/HDL & $3.7 \pm 0.24$ & $3.9 \pm 0.11$ & NS & $3.98 \pm 0.18$ & $3.85 \pm 0.13$ & NS \\
\hline TG/HDL & $2.95 \pm 0.18$ & $3.2 \pm 0.4$ & NS & $3.8 \pm 0.86$ & $2.8 \pm 0.37$ & NS \\
\hline LDL/HDL & $2.12 \pm 0.21$ & $2.3 \pm 0.1$ & NS & $3.2 \pm 2.7$ & $0.5 \pm 0.03$ & NS \\
\hline CRP mg/L & $0.57 \pm 0.02$ & $0.98 \pm 0.1$ & 0.001 & $1.1 \pm 0.19$ & $0.93 \pm 0.12$ & NS \\
\hline Hs CRP mg/L & $0.19 \pm 0.02$ & $1.07 \pm 0.16$ & 0.001 & $1.2 \pm 0.32$ & $0.98 \pm 0.18$ & NS \\
\hline ALT U/L & $24.8 \pm 1.1$ & $15.7 \pm 0.71$ & 0.001 & $15.8 \pm 1.0$ & $15.6 \pm 0.95$ & NS \\
\hline AST U/L & $23.7 \pm 1.2$ & $17.1 \pm 1.0$ & 0.001 & $16.8 \pm 1.6$ & $17.3 \pm 1.3$ & NS \\
\hline GGT U/L & $20.7 \pm 0.9$ & $17.4 \pm 0.6$ & 0.010 & $17.5 \pm 0.9$ & $17.4 \pm 0.8$ & NS \\
\hline T. Bilirubin mg/dL & $0.72 \pm 0.04$ & $0.68 \pm 0.01$ & NS & $0.68 \pm 0.02$ & $0.68 \pm 0.01$ & NS \\
\hline T. Protein g/dL & $7.0 \pm 0.08$ & $6.9 \pm 0.03$ & NS & $6.99 \pm 0.04$ & $6.9 \pm 0.04$ & NS \\
\hline Albumin g/L & $4.03 \pm 0.12$ & $3.97 \pm 0.04$ & NS & $4.1 \pm 0.06$ & $3.9 \pm 0.06$ & NS \\
\hline Globulin g/dL & $2.95 \pm 0.05$ & $2.97 \pm 0.02$ & NS & $2.9 \pm 0.03$ & $3.0 \pm 0.03$ & NS \\
\hline iPTH pg/mL & $32.1 \pm 2.6$ & $43.8 \pm 4.5$ & NS & $47.6 \pm 7.5$ & $41.8 \pm 5.8$ & NS \\
\hline B-ALP $\mu g / L$ & $8.8 \pm 0.73$ & $437.8 \pm 51.3$ & 0.001 & $470.4 \pm 97.9$ & $419.7 \pm 59.2$ & NS \\
\hline ALP U/L & $68.7 \pm 3.8$ & $250.7 \pm 26.1$ & 0.001 & $277.7 \pm 54.7$ & $235.7 \pm 27.1$ & NS \\
\hline Phosphorous mg/dL & $3.3 \pm 0.24$ & $8.8 \pm 0.2$ & 0.001 & $8.85 \pm 0.36$ & $8.87 \pm 0.25$ & NS \\
\hline Calcium mg/dL & $9.7 \pm 0.18$ & $5.4 \pm 0.24$ & 0.001 & $5.1 \pm 0.4$ & $5.5 \pm 0.3$ & NS \\
\hline Ca $\times P$ & $31.5 \pm 1.9$ & $46.5 \pm 2.1$ & 0.001 & $44.7 \pm 3.5$ & $47.4 \pm 2.7$ & NS \\
\hline
\end{tabular}

Table 3: Mortality rate among patients according to Gender/Age.

\begin{tabular}{|c|c|c|c|c|c|c|}
\hline & Males $<60$ & Males $>=60$ & Females $<60$ & Females $>=60$ & Total & $\chi^{\mathbf{2}}$ \\
\cline { 1 - 5 } Survived & $11(37.9 \%)^{*}$ & $7(31.8 \%)$ & $3(30 \%)$ & $4(44 \%)$ & $25(35.7 \%)$ & \multirow{2}{*}{ NS } \\
\hline Died & $18(62.1 \%)$ & $15(68.2 \%)$ & $7(70 \%)$ & $5(55.6 \%)$ & $45(64.3 \%)$ & \\
\hline
\end{tabular}

*=Number $(\%$ within subgroup) 
Analysis of biochemical parameters as predictors of cardiovascular mortality

We did not find any significant differences in the studied parameters between patients who survived 4 years during the follow-up, and those who died. Similar observation was found when patients were categorized into men and women (Table 2).

Conversely, after subdividing the patients according to gender and age $(<60$, or $\geq 60$ years $)$, deceased women had significant differences in their markers compared to those who survived (Figure 1). Deceased women younger than 60 years had lower albumin $(3.9 \pm 0.23 \mathrm{vs}$. $4.4 \pm 0.22 \mathrm{~g} / \mathrm{dL}, \mathrm{p}<0.04)$, and higher globulin than those who survived $(3.2 \pm 0.08$ vs. $2.7 \pm 0.12 \mathrm{~g} / \mathrm{dL}, \mathrm{p}<0.023)$ (Figure 1). On the other hand, deceased women older than 60 years, had lower urea $(114 \pm 2.4$ vs. $135.8 \pm 7.4$ $\mathrm{g} / \mathrm{dL}, \mathrm{p}<0.03)$ and Hs CRP $(0.6 \pm 0.23$ vs. $2.9 \pm 1.5$ $\mathrm{mg} / \mathrm{dL}, \mathrm{p}<0.05)$ levels. In addition, they had higher levels of $\mathrm{LDL}(81.7 \pm 7.3$ vs. $45.2 \pm 15.5 \mathrm{mg} / \mathrm{dL}$, $\mathrm{p}<0.05)$, LDL/HDL (0.45 \pm 0.03 vs. $17.5 \pm 16.9, \mathrm{p}<0.03)$, and B-ALP activity $(349.7 \pm 110 v s .76 .7 \pm 20.5 \mu \mathrm{g} / \mathrm{L}$, $\mathrm{p}<0.05)$, (Figure 1). No significant differences were found among men patients.

Calculation of the cutoff values and their diagnostic probability

ROC curves for survival were done for women at both age categories. The cut-off values, and their sensitivity, specificity, Chi-square $\left(x^{2}\right)$, and likelihood ratio (LR) are shown in Table 4. Although the sensitivity (results for deceased), and specificity (results for survived) were high, the significance $\left(x^{2}\right)$, and LR are not very high, due to the small number of patients in these groups.

\section{Discussion}

Biochemical and physiological abnormalities in chronic kidney disease are associated with the attempts of the human body to maintain homeostasis despite progressive loss of nephrons and impaired kidney function. Multiple adaptive and maladaptive processes occurring at that time affect mainly the cardiovascular, neurological, hematological, musculoskeletal, and immunological systems ${ }^{[34,35]}$.
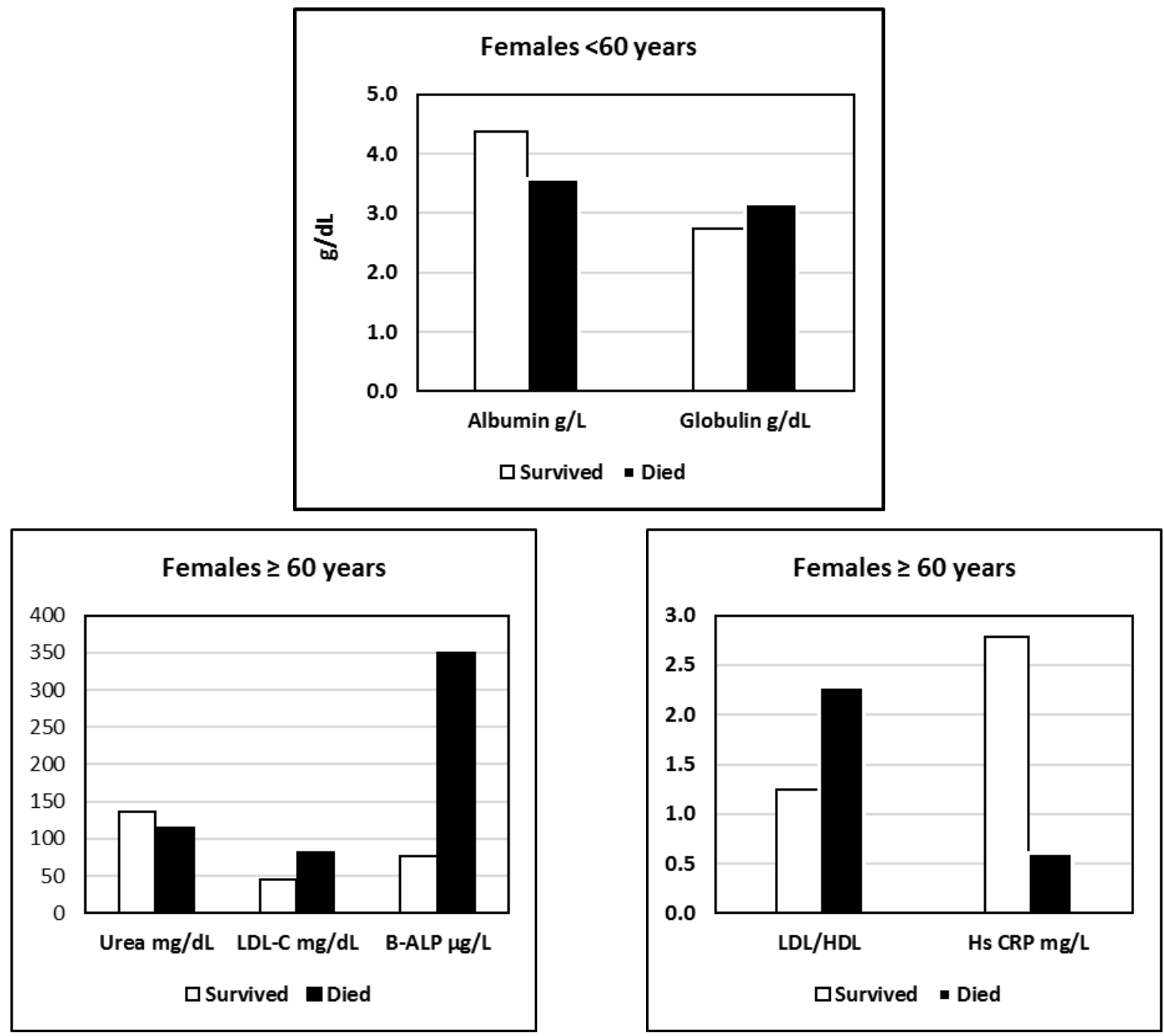

Fig. 1: Significant changes among women according to survival and age. 
Table 4: Cross-tabulation for significance of cutoff values (from ROC curves) for women.

\begin{tabular}{|c|c|c|c|c|c|}
\hline & & \multicolumn{2}{|c|}{ Survival } & \multirow[b]{2}{*}{$\chi^{2}$} & \multirow[b]{2}{*}{ LR } \\
\hline Marker & Marker cutoff & Survived & Died & & \\
\hline \multicolumn{6}{|c|}{ Women < 60 years } \\
\hline \multirow{2}{*}{ Albumin g/dL } & Albumin $<4.05$ & $0(0 \%)^{*}$ & $7(100 \%)$ & \multirow{2}{*}{0.002} & \multirow{2}{*}{12.2} \\
\hline & Albumin $\geq 4.05$ & $3(100 \%)$ & $0(0 \%)$ & & \\
\hline \multirow{2}{*}{ Globulin g/dL } & Globulin<2.95 & $3(100 \%)$ & $1(14.3 \%)$ & \multirow{2}{*}{0.01} & \multirow{2}{*}{7.7} \\
\hline & Globulin $\geq 2.95$ & $0(0 \%)$ & $6(85.5 \%)$ & & \\
\hline \multicolumn{6}{|c|}{ Women $\geq 60$ years } \\
\hline \multirow{2}{*}{ Urea mg/dL } & Urea $<127$ & $1(25 \%)$ & $5(100 \%)$ & \multirow{2}{*}{0.018} & \multirow{2}{*}{7} \\
\hline & Urea $>=127$ & $3(75 \%)$ & $0(0 \%)$ & & \\
\hline \multirow{2}{*}{ LDL mg/dL } & $\mathrm{LDL}<71.5$ & $4(100 \%)$ & $1(20 \%)$ & \multirow{2}{*}{0.016} & \multirow{2}{*}{7.4} \\
\hline & $\mathrm{LDL}>=71.5$ & $0(0 \%)$ & $4(80 \%)$ & & \\
\hline \multirow{2}{*}{ LDL/HDL } & LDL/HDL $<1.695$ & $3(75 \%)$ & $0(0 \%)$ & \multirow{2}{*}{0.018} & \multirow{2}{*}{7} \\
\hline & LDL/HDL>=1.695 & $1(25 \%)$ & $5(100 \%)$ & & \\
\hline \multirow{2}{*}{ HS CRP mg/dL } & HS CRP $<0.71$ & $0(0 \%)$ & $4(80 \%)$ & \multirow{2}{*}{0.016} & \multirow{2}{*}{7.4} \\
\hline & $\mathrm{HS}$ CRP $>=0.71$ & $4(100 \%)$ & $1(20 \%)$ & & \\
\hline \multirow{2}{*}{ B-ALP $\mu g / L$} & B-ALP<123.9 & $4(100 \%)$ & $1(20 \%)$ & \multirow{2}{*}{0.016} & \multirow{2}{*}{7.4} \\
\hline & $\mathrm{B}-\mathrm{ALP}>=123.9$ & $0(0 \%)$ & $4(80 \%)$ & & \\
\hline
\end{tabular}

*=Number (\% within subgroup $\equiv$ specificity (+ve survived) and sensitivity (+ve died) IHD $^{\mathrm{a}}$ : Ischemic heart disease

$\mathrm{CC}^{\mathrm{b}}$ : Cardiovascular complications.

$\mathrm{LR}^{\mathrm{c}}$ : Likelihood ratio

The present study explored the possible markers for cardiovascular mortality in patients maintained on hemodialysis, based on simple available clinical and laboratory tests.

\section{Markers related to ESRD}

Progressive left ventricular enlargement seems to be the most characteristic morphological pattern of patients who underwent hemodialysis, and is one of the key prognostic factors for cardiovascular mortality rates in

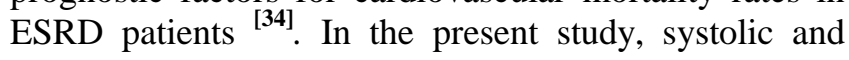
diastolic dimensions of the left ventricle as well as left ventricular mass differed significantly between ESRD patients and controls. Numerous studies have demonstrated that diastolic dysfunction, which is common in CKD, accounts for $40 \%-66 \%$ of cardiovascular complications [36,37]. Low ejection fraction and frequent mitral and tricuspid regurgitation observed in CKD patients in the present work is consistent with the results of other studies. It has been observed that the calcification process is common and more severe in the CKD population compared with healthy people ${ }^{[34]}$.

The results of biochemical parameters revealed significant reduction in hemoglobin, hematocrit, lipid profile (cholesterol, triglycerides, LDL, and HDL), and liver enzymes (AST, ALT, GGT), together with calcium. Increased levels of creatinine, urea, inflammation markers (CRP, Hs-CRP), and bone turnover parameters (ALP, bone-ALP, phosphorous, and calcium $\mathrm{x}$ phosphorous) were observed in patients with ESRD as compared with the reference ranges. These results are consistent with previous recent reports ${ }^{[3,34,38,39,40]}$ and are related to kidney damage.

Decreased levels of hemoglobin and hematocrit are not surprising since CKD patients frequently suffer from anemia ${ }^{[\mathbf{4 1 , 4 2}]}$. In these patients, anemia relates to three main factors: insufficient production of erythropoietin; impaired management of iron; and decreased lifespan of red blood cells (RBCs) ${ }^{[43]}$.

Systemic inflammation plays a major role in the development of atherosclerosis leading to coronary heart disease. C-reactive proteins (CRP\& Hs CRP) are acute phase reactants, and are established markers of systemic inflammation in the general population and patients with CKD ${ }^{[3,34]}$. Significant elevated concentrations of urea and creatinine in patients with ESRD are not astonishing, since these are well-known markers of kidney damage [34] 
It is believed that lipid abnormalities are a common phenomenon in patients with kidney disease. In the early stages of kidney disease, lipid profile may remain in the normal range, but with the progression of CKD hypertriglyceridemia, increased concentrations of total cholesterol, LDL and decreased HDL cholesterol appear [44,45]. However, in the present study significant decreased concentrations of total cholesterol, triglycerides, HDL, and LDL cholesterol in ESRD patients compared to healthy volunteers were observed. This could be due to hypervolemia ${ }^{[46]}$. Additionally, high-density lipoprotein (HDL) cholesterol was reported to be subnormal in the majority of patients, which is consistent with the results of Gluba-Brzózka et al. ${ }^{[34]}$. Uremia causes qualitative changes in the composition of LDL, increases the number of small-dense LDL particles and facilitates their oxidation and glycation. LDL cholesterol in CKD may be normal or decreased ${ }^{[46]}$.

Since the 1970s, studies, including the present one, have shown that AST and ALT serum levels were decreased in ESRD patients. It was hypothesized that this reduction could be caused by factors such as high lactate serum levels; presence of uremic factors that would inhibit the activity of these enzymes; and, finally, the deficiency of pyridoxine, a cofactor for the synthesis of the aminotransferases ${ }^{[47,48]}$.

It seems that pronounced severity of atherosclerosis in patients with ESRD may also be associated with disorders of calcium-phosphate metabolism [49]. Impaired excretion of phosphate leads to its increased concentration, binding with calcium in tissues and the accumulation of inorganic phosphate in the arteries. This cascade increases the risk of heart attack and stroke ${ }^{[49,50]}$. High levels of phosphate usually appear when the GFR falls below $60 \mathrm{ml} / \mathrm{min}$ and worsens with the deterioration of renal excretory functions. Hyperphosphatemia stimulates parathyroid glands to increased secretion of parathyroid hormone (PTH), which in turn increases the release of phosphate from the bone, contributing to further accumulation of phosphate in serum ${ }^{[51]}$. High levels of inorganic phosphate in ESRD patients observed in this study are in accordance with the results of other studies ${ }^{[38,49,51]}$.

\section{Markers related to mortality}

The pathogenesis of cardiovascular damage in chronic renal disease is more complex in comparison to other general population. For monitoring mortality, it is of great importance from the very beginning of hemodialysis-treatment to monitor the percentage of the so called non-traditional risk factors for cardiovascular disease. For decades, hypertension, diabetes mellitus, hyperlipidemia, obesity, smoking, and low physical activity/inactivity are known to affect the occurrence of cardiovascular diseases and they represent the traditional risk factors ${ }^{[52]}$. The contribution of traditional risk factors does not fully explain the high frequency of cardiovascular mortality in ESRD, and thus scientists look for new mechanisms involved in its pathogenesis (recently reviewed by Floege et al. ${ }^{[35]}$ ). The incorpor- ation of simple renal biomarkers in the clinical practice for CVD prevention could be accomplished quickly, and would be useful to prevent cardiovascular complications [53]

In the present study all deceased patients had cardiovascular complications. However, we were not able to detect any specific marker for mortality in total patients, total men, or total women. However, after dividing each gender according to age $(<$ or $\geq 60$ years), deceased women showed some differences from the survivors.

Compared to survivors, deceased women younger than 60 years $(70 \%)$ showed lower albumin $(<4.05 \mathrm{~g} / \mathrm{dL})$ and higher globulin (>2.95 g/dL) levels. These cut-off values correspond to $100 \%$ specificity for both proteins, with $100 \%$ and $80 \%$ sensitivity, respectively.

Previous studies stated that serum albumin level predicts mortality in dialysis patients, and a significant increase in death risk was evident in patients subjected to $\mathrm{HD}$ with serum albumin level $<4.0 \mathrm{~g} / \mathrm{dL}^{[54,55,56]}$. It was reported that patients in whom serum albumin declines by as little as $0.2 \mathrm{~g} / \mathrm{dl}$ have a higher risk for death, irrespective of the baseline serum albumin ${ }^{[56]}$. According to de Mutsert et al. ${ }^{[57]}$, the mortality risks associated with serum albumin were not a consequence of malnutrition, but are secondary to the confounding influence of systemic inflammation, since albumin is a negative acute phase reactant. In addition, recent cross-sectional studies suggested that many of ESRD patients with hypoalbuminemia, are volume overloaded and hypervolemia may be an additional confounding influence ${ }^{[52,56]}$. Alternatively, globulins; including beta(2)-microglobulin, are recognized as surrogate markers of middle-molecule uremic toxins, and key components in the genesis of dialysis-associated amyloidosis, consequently, they are important predictors for mortality in patients maintained on HD ${ }^{[58]}$. The reason for the association between these markers and mortality rate in only this subgroup of patients is unknown.

Older women ( $\geq 60$ years), on the other hand, showed completely different mortality markers. In this subgroup 5 patients died out of 9 women (56\%).The deceased women had higher LDL, LDL/HDL, and bone ALP, with cutoff values and specificity of $71.5(100 \%), 1.695$ (75\%), and $123.9(100 \%)$ respectively. The sensitivities of these markers were $80 \%$ for LDL, $100 \%$ for LDL/HDL, and $80 \%$ for B-ALP.

LDL and HDL are crucially involved in the pathogenesis of atherosclerotic cardiovascular diseases. It is well known that LDL may promote the formation of vascular atherosclerotic lesions. In contrast, HDL has commonly been thought to act as a vasoprotective agent mainly by preventing endothelial dysfunction that reflects the initial step of atherosclerosis ${ }^{[59]}$. However, there is a growing body of evidence indicating that HDL may lose its vasoprotective properties in certain clinical conditions (diabetes and cardiovascular diseases) ${ }^{[60]}$. In line with these findings, Zewinger and co-workers ${ }^{[40]}$ showed that 
even in patients with incipient CKD, HDL is transformed into a noxious particle inducing endothelial dysfunction and arterial hypertension. Interestingly, a study by Voight et al. ${ }^{[61]}$ failed to demonstrate a beneficial effect of genetically elevated HDL cholesterol (HDL-C) serum levels on the rate of cardiovascular events. Moreover, increasing HDL-C serum levels using pharmacologic inhibitors of the cholesterol-ester transfer protein did not reduce the rate of cardiovascular events [59].

In agreement with the present results, growing recent data is available linking high ALP to the development of uremic vascular calcification. Beige et al. ${ }^{[62]}$ found that serum ALP, which is correlated to B-ALP, is associated with coronary artery calcification, cardiovascular-related mortality and all-cause mortality in patients with ESRD and maintained on HD, whereas patients with lower BALP had better survival rate.

Deceased women (above 60 years) also had low urea and Hs-CRP levels. However, both values were higher than the normal range. The decreased levels of these markers could be due to hypervolemia, and/or due to the use of anti-inflammatory drugs (aspirin), which significantly contributes to the reduction of CRP ${ }^{[52]}$.

\section{Conclusion}

In patients maintained on hemodialysis both sexes face increased risk of cardiovascular complications. However, gender and age together play a significant role in determining biochemical predictors for cardiovascular mortality. Further studies with different simple biochemical parameters are required with larger number of patients, covering different age groups.

\section{References}

1) Franczyk-Skóra, B., Gluba, A., Olszewski, R., Banach, M. and Rysz, J. (2014). Heart function disturbances in chronic kidney disease echocardiographic indices. Arch. Med. Sci., 10(6): 1109-1116.

2) D'Marco, L., Bellasi, A. and Raggi, P. (2015). Cardiovascular biomarkers in chronic kidney disease: state of current research and clinical applicability. Dis. Markers, 2015: 586-569.

3) Mohandas, R., Segal, M. S., Huo, T., Handberg, E. M., Petersen, J. W., Johnson, B. D., Sopko, G., Bairey Merz, C. N. and Pepine, C. J. (2015). Renal function and coronary microvascular dysfunction in women with symptoms/signs of ischemia. PLoS One, 10(5): e0125374.

4) Cox, A. J., Hsu, F. C., Carr, J. J., Freedman, B. I. and Bowden, D. W. (2013). Glomerular filtration rate and albuminuria predict mortality independently from coronary artery calcified plaque in the Diabetes Heart Study. Cardiovasc Diabetol., 12: 68.

5) Degrassi, F., Quaia, E., Martingano, P., Cavallaro, M. and Cova, M. A. (2015). Imaging of haemodialysis renal and extrarenal findings. Insights Imaging, 6(3): 309-321.
6) Jaffe, M. (1886). Ueber den Niederschlag welchen Pikrinsa"ure in normalen Harn erzeugt und ueber eine neue Reaktion des Kreatinins. Z Physiol Chem., 10: 391-400.

7) Batton, C. J., and Crouch, S. R. (1977). Estimation of Urea. Anal. Chem., 49: 464-469.

8) Trinder, P. (1969). Determination of glucose in blood using glucose oxidase with an alternative oxygen receptor. Ann. Clin. Biochem., 6: 24-27.

9) Cali, J. P., Mandel, J., Moore, L. J. and Young, D. S. (1972). A reference method for the determination of $\mathrm{Ca}$ in serum. NBS sp. Publication. 260: 32-36.

10) Gomorri, G. (1942). Modification of the colorimetric phosphorus determination for use with the photoelectric colorimeter. J. Lab. Clin. Med., 27: 955-960.

11) Reitman, S. and Frankel, S., A. (1956). Colorimetric method for the determination of serum glutamic oxalacetic and glutamic pyruvic transaminases. Am J Clin Pathol., 28(1): 56-63.

12) Szasz, G. (1969). A kinetic photometric method for serum gamma-glutamyl transpeptidase. Clin Chem., 15(2): 124-136.

13) Ehrlich, P. (1877). Beiträge zur Kenntnis der Anilinfärbungen und ihrer Verwendung in der mikroskopischen Technik. Archiv fuer mikroskopische Anatomie, 13: 263-278.

14) Gornall, A. G., Bardawill, C. J. and David, M. M. (1949). Determination of serum proteins by means of the biuret reaction. J. Biol. Chem., 177(2): 751-766.

15) Faulkner, W. R., and Meites, S. (1982). Selected methods of clinical chemistry. American Association for Clinical Chemistry Washington, DC., 9: 312-319.

16) Bartholomew, R. J., and Delaney, A. M. (1966). Sulphonphthaleins as specific reagents for albumin: determination of albumin in serum. Proc Aust Assoc Clin Biochem., 1:214-218.

17) Rodkey, F. L. (1964). Tris (Hydroxymethyl) aminomethane as a standard for kjeldahl nitrogen analysis. Clin Chem., 10 :606-610.

18) Tietz, N. W., Rinker, A. D., and Shaw, L. M. (1983). IFCC methods for the measurement of catalytic concentration of enzymes Part 5. IFCC method for alkaline phosphatase (orthophosphoricmonoester phosphohydrolase, alkaline optimum, EC 3.1.3.1). J. Clin. Chem. Clin. Biochem., 21(11): 731748.

19) Kress, B. C., Nielsen, R., Broyles, D., Noell, J., Ngo, T., Bussett, E., Lu, W., Nunnelly, P. and Mizrahi, I. (1999). Performance characteristics of the ACCESS Ostase Assay, chemiluminescent assay for serum bone-specific alkaline phosphatase on the ACCESS Immunoassay System. Clinical Chemistry, 45(6): A104.

20) Glendenning, P., Musk, A. A., Taranto, M., and Vasikaran, S. D. (2002). Preanalytical factors in the measurement of intact parathyroid hormone with the DPC IMMULITE assay. Clin. Chem., 48:566-567. 
21) Bind, E., Schmidt-Gayk, H., Scharla, S., Flentje, D., Fischer S., Goehring, U. and Hitzler, W. (1988). Two-site assay of intact parathyroid hormone in the investigation of primary hyperparathyroidism and other disorders of calcium metabolism compared with a midregion assay. J. Clin. Endocrinol. Metab., 67: 353-360.

22) Otsuji, S., Shibata, H. and Umeda, M. (1982). Turbidimetric immunoassay of serum C-reactive protein. Clin. Chem., 28: 2121-2124.

23) Osmand, A. P., Friedenson, B., Gewurz, H., Painter, R. H., Hofmann, T. and Shelton, E. (1977). Characterization of C-reactive protein and the complement subcomponent $\mathrm{C} 1 \mathrm{t}$ as homologous proteins displaying cyclic pentameric symmetry (pentraxins). Proc. Natl. Acad. Sci. USA, 74(2): 739-743.

24) Flegg, H. M. (1973). An investigation of the determination of serum cholesterol by an enzymatic method. Ann. Clin. Biochem., 10: 79-84.

25) Richmond, W. 1973. Preparation and properties of a bacterial cholesterol oxidase from Nocardia sp. and its application to enzyme assay of total cholesterol in serum. Clinical Chemistry, 19: 13501356.

26) Buccolo, G. and David, H. (1973). Quantitative determination of serum triglycerides by the use of enzymes. Clin. Chem., 19(5): 476-482.

27) McDown, M. W., Artiss, J. D., Strandbergh, D. R. and Zak, B. (1983). A peroxidase-coupled method for the colorimetric determination of serum triglycerides. Clin. Chem., 29(3): 538-542.

28) Finley, P. R., Schifman, R. B. and Williams, R. J. (1978). Cholesterol in HDL: use of $\mathrm{Mg}^{2+} /$ dextran sulphate in its enzymatic measurement. Clin. Chem., 24: 931-933.

29) Warnick, G. R., Benderson, J. and Albers, J. J. (1983). Dextran-sulfate- $\mathrm{Mg}^{2+}$ precipitation procedure for quantitation of high density lipoprotein cholesterol. Cooper GR eds. Selected methods of clinical chemistry American Association for Clinical Chemistry Washington, DC. 10: 91-99.

30) Choo, Q. L., Kuo, G., Weiner, A. J., Overby, L. R., Bradley, D. W. and Houghton, M. (1989). Isolation of a cDNA clone derived from a bloodborne non-A, non-B viral hepatitis genome. Science, 244: 359-362.

31) Wolters, G., Kuijpers, L. P., Kacaki, J. and Schuurs, A. H. (1977). Enzyme linked immunoasorbent essay for hepatitis B surface antigen. J. Infect. Dis., 136: 311-317.

32) Tiez, N. W. (1976). Fundamentals of Clinical Chemistry, W.B. Saunders Co., Philadelphia, p. 411.

33) Purves, W.K., David, S., Gordon, H.O., Orians, H. and Heller, C. (2004). Life: The Science of Biology $\left(7^{\text {th }}\right.$ ed.). Sunderland, Mass: Sinauer Associates. p. 954.

34) Gluba-Brzózka, A., Michalska-Kasiczak, M., Franczyk-Skóra, B., Nocuń, M., Banach, M. and
Rysz, J. (2014). Markers of increased cardiovascular risk in patients with chronic kidney disease. Lipids Health Dis., 13: 135.

35) Floege, J., Gillespie, I. A., Kronenberg, F., Anker, S. D., Gioni, I., Richards, S., Pisoni, R. L., Robinson, B. M., Marcelli, D., Froissart, M. and Eckardt, K. U. (2015). Development and validation of a predictive mortality risk score from a European hemodialysis cohort. Kidney Int., 87(5): 996-1008.

36) Wang, A. Y. M., Wang, M., Lam, C. W. K., Chan, I. H. S., Zhang, Y. and Sanderson, J. E. (2008). Left ventricular filling pressure by Doppler echocardiography in patients with end-stage renal disease. Hypertension, 52(1): 107-114.

37) Arodiwe, E. B., Ulasi, I. I., Ijoma, C. K. and Ike, S. O. (2010). Left ventricular diastolic function in a predialysis patient population. West Afr. J. Med., 29(4): 225-229.

38) Fahrleitner-Pammer, A., Herberth, J., Browning, S. R., Obermayer-Pietsch, B., Wirnsberger, G., Holzer, H., Dobnig, H. and Malluche, H. H. (2008). Bone markers predict cardiovascular events in chronic kidney disease. J. Bone Miner. Res., 23(11): 1850-1858.

39) Martínez-Castelao, A. I., Górriz, J. L., Portolés, J. M., De Alvaro, F., Cases, A., Luño, J., NavarroGonzález, J. F., Montes, R., De la Cruz-Troca, J. J., Natarajan, A. and Batlle, D. (2011). Baseline characteristics of patients with chronic kidney disease stage 3 and stage 4 in Spain: the MERENA observational cohort study. BMC Nephrol., 12: 53.

40) Zewinger, S., Speer, T., Kleber, M. E., Scharnagl, H., Woitas, R., Lepper, P. M., Pfahler, K., Seiler, S., Heine, G. H., März, W., Silbernagel, G. and Fliser, D. (2014). HDL cholesterol is not associated with lower mortality in patients with kidney dysfunction.J. Am. Soc. Nephrol., 25(5): 1073-1082.

41) Nurko, S. (2006). Anemia in chronic kidney disease: causes, diagnosis, treatment. Cleve Clin. J. Med., 73(3): 289-297.

42) Kaze, F. F., Kengne, A. P., Mambap, A. T., Halle, M. P., Mbanya, D. and Ashuntantang, G. (2015). Anemia in patients on chronic hemodialysis in Cameroon: prevalence, characteristics and management in low resources setting. Afr. Health Sci., 15(1): 253-260.

43) Stamopoulos, D., Bakirtzi, N., Manios, E. and Grapsa, E. (2013). Does the extracorporeal circulation worsen anemia in hemodialysis patients? Investigation with advanced microscopes of red blood cells drawn at the beginning and end of dialysis. Int. J. Nanomedicine, 8: 3887-3894.

44) Piecha, G., Adamczak, M. and Ritz, M. (2009). Dyslipidemia in chronic kidney disease. Pathogenesis and intervention. Pol. Arch. Med. Wewn., 119(7-8): 487-492.

45) Nikolic, D., Banach, M., Nikfar, S., Salari, P., Mikhailidis, D. P., Toth, P. P., Abdollahi, M., Ray, K. K., Pencina, M. J., Malyszko, J., Rysz, J. and 
Rizzo, M. (2013). Lipid and blood pressure metaanalysis collaboration group: a meta-analysis of the role of statins on renal outcomes in patients with chronic kidney disease. Is the duration of therapy important? Int. J. Cardiol., 168(6): 5437-5447.

46) Nikolic, D., Nikfar, S., Salari, P., Rizzo, M., Ray, K. K., Pencina, M. J., Mikhailidis, D. P., Toth, P. P., Nicholls, S. J., Rysz, J., Abdollahi, M. and Banach, M. (2013). Lipid and blood pressure metaanalysis collaboration group: effects of statins on lipid profile in chronic kidney disease patients: a meta-analysis of randomized controlled trials. Curr. Med. Res. Opin., 29(5): 435-451.

47) Ono, K., Ono, T. and Matsumata, T. (1995). The pathogenesis of decreased aspartate aminotransferase and alanine aminotransferase activity in the plasma of hemodialysis patients: the role of vitamin B6 deficiency. Clin. Nephrol., 43(6): 405-408.

48) Kobayashi, I., Shidara, K., Okuno, S., Yamada, S., Imanishi, Y., Mori, K., Ishimura, E., Shoji, S., Yamakawa, T. and Inaba, M. (2012). Higher serum bone alkaline phosphatase as a predictor of mortality in male hemodialysis patients. Life Sci., 90(5-6): 212-218.

49) Sette, L. H. and Almeida Lopes, E. P. (2014). Liver enzymes serum levels in patients with chronic kidney disease on hemodialysis: a comprehensive review. Clinics (Sao Paulo), 69(4): 271-278.

50) Roberts, D. M. and Singer, R. F. (2010). Management of renal bone disease. Aust. Prescr., 33: 34-37.

51) Lertdumrongluk, P., Lau, W. L., Park, J., Rhee, C. M., Kovesdy, C. P. and Kalantar-Zadeh, K. (2013). Impact of age on survival predictability of bone turnover markers in hemodialysis patients. Nephrol. Dial. Transplant., 28(10): 2535-2545.

52) Coric, A., Resic, H., Celik, D., Masnic, F, Ajanovic, S., Prohic, N., Beciragic, A., Grosa, E., Smajlovic, A. and Mujakovic, A. (2015). Mortality in hemodialysis patients over 65 years of age. Mater. Sociomed., 27(2): 91-94.

53) Donfrancesco, C., Palleschi, S., Palmieri, L., Rossi, B., Lo Noce, C., Pannozzo, F., Spoto, B., Tripepi, G., Zoccali, C. and Giampaoli, S. (2013). Estimated glomerular filtration rate, all-cause mortality and cardiovascular diseases incidence in a low risk population: the MATISS study. PLoS One,
8(10): e78475.

54) Foley, R. N., Parfrey, P. S., Harnett, J. D., Kent, G. M., Murray, D. C. and Barre, P. E. (1996). Hypoalbuminemia, cardiac morbidity, and mortality in end-stage renal disease. J. Am. Soc. Nephrol., 7(5): 728-736.

55) Kalantar-Zadeh, K., Kilpatrick, R. D. and Kuwae, N. (2005). Revisiting mortality predictability of serum albumin in the dialysis population: time dependency, longitudinal changes and populationattributable fraction. Nephrol. Dial. Transplant., 20(9): 1880-1888.

56) Mehrotra, R., Duong, U., Jiwakanon, S., Kovesdy, C. P., Moran, J., Kopple, J. D. and KalantarZadeh, K. (2011). Serum albumin as a predictor of mortality in peritoneal dialysis: comparisons with hemodialysis.Am. J. Kidney Dis., 58(3): 418-428.

57) de Mutsert, R., Grootendorst, D. C., Indemans, F., Boeschoten, E. W., Krediet, R. T. and Dekker, F. W. (2009). Association between serum albumin and mortality in dialysis patients is partly explained by inflammation, and not by malnutrition. J. Ren. Nutr., 19(2): 127-135.

58) Okuno, S., Ishimura, E., Kohno, K., FujinoKatoh, Y., Maeno, Y., Yamakawa, T., Inaba, M. and Nishizawa, Y. (2009). Serum beta-2microglobulin level is a significant predictor of mortality in maintenance haemodialysis patients.Nephrol. Dial. Transplant., 24(2): 571-577.

59) Barter, P., Gotto, A. M., LaRosa, J. C., Maroni, J., Szarek, M., Grundy, S. M., Kastelein, J. J., Bittner, V. and Fruchart, J. C. (2007). Treating to New Targets Investigators: HDL cholesterol, very low levels of LDL cholesterol, and cardiovascular events. New Engl. J. Med., 357: 1301-1310.

60) Mineo, C. and Shaul, P. W. (2012). Novel biological functions of high-density lipoprotein cholesterol. Circ. Res., 111: 1079-1090.

61) Voight, B. F., Peloso, G. M. and Orho-Melander, M. (2012). Plasma HDL cholesterol and risk of myocardial infarction: A mendelian randomisation study. Lancet, 380: 572-580.

62) Beige, J., Wendt, R., Girndt, M., Queck, K. H., Fiedler, R. and Jehle, P. (2014). Association of serum alkaline phosphatase with mortality in nonselected European patients with CKD5D: an observational, three-centre survival analysis. BMJ Open, 4(2): e004275. 